\title{
Construction of Evaluation Index System of the New Generation Migrant
}

\section{Workers' Employment Quality}

\author{
Li Qian, Chen Wanming \\ College of Economics and Management \\ Nanjing University of Aeronautics and Astronautics, Nanjing 211106, China \\ Email: 13770968181@163.com
}

\begin{abstract}
The "supply side" structural reform is an innovative reform to improve the level of social productivity and other important mission. From the perspective of public management, it is bound to deal with the transformation of migrant workers and improve the quality of employment of them in the supply side of structural reform to obtain the success of reform. The reasonable index system is the key to evaluate the quality of the new generation of migrant workers employment. According to the characteristics of the new generation of migrant workers, According to the characteristics of the new generation of migrant workers, the evaluation index of the new generation of migrant workers employment quality is divided into two categories, objective and subjective index, namely the circumstances they are engaged in work, and the subjective evaluation of employment situation. In addition to the job satisfaction index, add a subjective evaluation indexes, employment expectation index, from settled intention, participate in management, to help to obtain employment these four specific dimensions to measure to eliminate employment discrimination. According to this idea to build the evaluation index system, through the Delphi method to determine the weight of indicators, provide a reference for the evaluation of the new generation of migrant workers" employment quality.
\end{abstract}

Keywords: the new generation of migrant workers, supply-side reform, quality of employment, the Delphi method, index system.

\section{Introduction}

The number of migrant workers in China reached 270 million in 2015, of which 130 million were the new generation migrant workers born after the 1980s, accounted for $48.2 \%$ of the total migrant workers. The number of the new generation of migrant workers has been more than 100 million in China since 2009, the new generation of migrant workers has become the main force of migrant workers. Yang Zhiming[1], director of the office of the State Council, the work leading group of migrant workers has said, China's migrant workers will reach 300 million by 2020.Facing the current national economic transformation, industrial structure optimization and upgrading, as well as the background of the aging of the rural migrant workers, new generation of migrant workers employment problem needs to be solved, the government should pay more attention on quality improvement rather than quantity increasing in numbers. Measured objectively and scientifically on the new generation of migrant workers' employment quality is the basic premise of the quality of employment, and establishing a scientific evaluation index system of employment quality is the most complex and difficult progress. Although the measurement of the quality of employment is different, the main representative point of view held by scholars are subjective and objective evaluation indexes. It has a good reference value for the research. 


\section{Concept Definition}

"The new generation of migrant workers" can be earliest traced back to 2001, Wang Chunguang proposed the new generation of rural floating population "concept. In the process of its formation, some scholars have called it "the second generation peasant workers", "young migrant workers", "a new generation of migrant workers" and so on. The central document formally established the "new generation of migrant workers" concept to take targeted measures to solve the problem of the new generation of migrant workers. National Federation of trade unions (2010), the National Federation of trade unions on the new generation of migrant workers in the study report, set out in the official website. The new generation of migrant workers is defined as people who was agricultural population, born after 1980s, at the age of 16 years or more, mainly engaged in non-agriculture work in another places. By analyzing the literature about the connotation of the new generation of migrant workers can be summarized as the following: firstly, from the birth, was born in 1980 and later; secondly, from the workers experience, have some certain working experience, and this is mainly distinguished from students; thirdly, from the social status, still retains the rural household registration. Summarized the current research achievements of many scholars, the new generation of migrant workers generally have the following characteristics: younger age, ranging from 16 to 35 years; a higher level of education, generally has a junior high school degree or above and no farming experience.

The concept of employment quality was arisen in the middle of the 1990s internationally .The study analyzed the influence of institutional factors on the quality of employment, age, political affiliation and other factors will affect the quality of employment, the research focus of follow-up is slowly turned to establish the evaluation index system of related problems with quantitative research method to explore the employment quality. [2]Liu Suhua [3]believes that the quality of employment, including employment of the nature of the employment, employment conditions, working environment, social security, labor relations, and other five aspects. The first domestic academic works on he quality of employment as the main focus of the report "2011 Chinese labor market report", the "report" that the factors involved in the quality of employment including employment environment, employment ability, employment status, workers compensation, social protection and labor relations and other aspects, and Chinese employment quality level is not high. Gao Wei [4]believes that (2012) the quality of employment is a multidimensional concept, a doping more subjective factors, it is defined as "a means of production workers and reflect the whole process of employment with and obtain the comprehensive category specific income of the extent of the. This study believes that the employment quality research is the employment activities, the combination of workers and production materials and income levels of the pros and cons. The factors that constitute such a good or bad is various, therefore, the content of the employment quality is various, mainly related to working conditions, working environment, labor remuneration, social security, labor relations.

\section{Review on The Evaluation Index System of The New Generation Of Migrant Workers' Employment Quality}

An important research from the European foundation, which is based on improving working and living conditions of the target shows an analysis framework for evaluation of employment quality, this framework later was used to analysis and comparison to Canada, the United States and 15 members of the European Union employment of a series of index data quality. According to the level of the quality of employment, Schroeder Frederic K (2007) further put forward the high quality of employment. He believes that high quality employment is a personal satisfaction and challenging integrated work environment to obtain the ability to pay for life, and stressed that income is not the only measure of high 
quality employment. The division of the quality of employment has developed with the deepening of research.

Domestic research on employment quality evaluation indexes more focused on urban workers and college groups, such as for a new generation of migrant workers employment quality evaluation index system of research started relatively late. Li Quanlin (2005) proposed employment quality measures should include objective indicators of employment level and subjective index comprehensive evaluation by both the employment satisfaction. Liu Suhua (2005) put forward from two aspects: subjective and objective to measure the quality of employment, to establish a quantitative measure the quality of our country enterprise employment system and the method, the democratic management, trade union organizations, social dialogue, equal consultation and collective contract, the four indicators set up $20 \%$ of the weight. Peng guosheng (2008) researched on the human capital and social capital respectively as independent variables[5-6]. Yao Yonggao divided the objective dimensions of young migrant workers' employment quality into four aspects: the occupation stability (usually the possibility of continuing a job for more than 6 months to measure),occupation income (including salary, bonuses, benefits and other benefits), occupation prestige (specific social prestige),occupation development opportunities (mainly including the occupation of upward mobility opportunities and flowing space).

Researches about the evaluation index of the employment quality abroad are more inclined to contain employees' personal will index into the employment quality evaluation system; domestic scholars pay more attention to factors of the work itself, and most of them agreed that the employment quality evaluation system mainly includes six types of indicators: the stability of wages, work time, work environment, occupation training, social security. For other evaluation indicators, such as career prospects, professional reputation, labor relations, etc. There is no unified view that whether other evaluation indicators should be included in the system of employment quality, such as career prospects, professional reputation, labor relations, etc. In short, the more detailed employment quality of the content of the system is divided into, the more favorable to the quality of employment to determine the merits of the situation. Domestic research began to bring subjective factors into the employment quality index system recent years, the index system for the employment quality content is not perfect, which can not objectively reflect the quality of employment situation.

According to this research, combined with the characteristics of the new generation of migrant workers, to measure the quality of employment from subjective and objective aspects. Objective evaluation indicators include work environment, wage payment, work stability and other indicators. The subjective evaluation index, emphasize the employment demands of the new generation of migrant workers, [7]they not only consider working environment and other factors when choosing jobs ,they are more involved in the management, settlement, city initiative rights and equal employment will, according to this, the research set up job satisfaction and employment expectations as the first-level indexes.

\section{Construction of Evaluation Index System of the New Generation Migrant Workers' Employment Quality}

This study evaluates employment quality of the new generation of migrant workers from the subjective and objective evaluation. The objective employment quality evaluation index should include employment, work environment, job availability, stability, labor standard setting and other aspects; the subjective evaluation index of employment quality should include individual subjective perception factors and factors closely related to work, such as job satisfaction, family harmony and so on; this study attempts to use the employment expectation and the job satisfaction indicators to reflect the subjective feeling, which makes the research results can be scientific and reasonable. 
This paper studies the extraction related factors. After the extraction, the evaluation system of employment quality mainly includes six kinds of indexes: wages, working hours, working environment, job training, social security and stability. In formulating the evaluation system of the new generation of migrant workers' employment quality, this study followed four basic principles: 1,comprehensiveness. The evaluation index system should reflect the content of the quality of employment in a comprehensive and scientific way. Such as social security, labor relations, work environment, wage income, etc, are the basic factors of the evaluation index system of the quality of employment. 2, Availability of availability. Each evaluation index data can be calculated through the survey data or directly obtained. The evaluation system of employment quality is the actual application of the specific departments, if it can not be applied, the design is complete, there is no sense. Evaluation factors also facilitate the statistical and measurement, some hidden, difficult to measure indicators can not be included in the evaluation index system. [8] 3, clarity. Each evaluation index is independent of the a certain aspect of the information of the general evaluation index, simple and clear, easy to understand and distinguish.4,Independence. Evaluation indicators are not included in each other.

In setting up the evaluation index system, this paper uses the existing research results for references, combined with the new generation of migrant workers" characteristics, determine the framework of generalized from the perspective of the new generation of migrant workers employment quality evaluation index system, including two dimensions of objective and subjective measures. The framework of the evaluation index system of the new generation migrant workers' employment quality evaluation index system is established, including the two dimensions of the objective and subjective indicators. The target layer is the new generation of migrant workers employment quality, the criterion layer is objective and subjective measures, formed the unfolding rule layer, operation layer formed, which constitutes a systematic, structured, independent index system, as shown in the table 1.

TABLE 1

The Evaluation Index System of the New Generation Migrant Workers' Employment Quality

\begin{tabular}{|c|c|c|c|}
\hline Symbol & First-level Indexes(2) & Second-level Indexes(4) & Third-level Indexes(16) \\
\hline $\begin{array}{l}\text { The } \\
\text { quality } \\
\text { of } \\
\text { employ } \\
\text { ment(U) }\end{array}$ & $\begin{array}{l}\text { Objective indexes } \\
(0.65)\end{array}$ & $\begin{array}{l}\text { Employment security } \\
\text { indexes }(C)(0.27)\end{array}$ & $\begin{array}{l}\text { I1 Wage payment }(0.62) \\
\text { I2Working hours }(0.21) \\
\text { I3Work environment }(0.13) \\
\text { I4Work stability }(0.04) \\
\text { C1 Sign labor contract }(0.64) \\
\text { C2Join trade unions }(0.07) \\
\text { C3Accept vocational training }(0.11) \\
\text { C4Pay social insurance }(0.18) \\
\text { E1Salary satisfaction }(0.43) \\
\text { E2Employer satisfaction }(0.25) \\
\text { E3workingconditionssatisfaction }(0.18) \\
\text { E4Interpersonal satisfaction }(0.14) \\
\text { S1Participation in management }(0.13) \\
\text { S2Eliminating discrimination }(0.35) \\
\text { S3More employment help }(0.31) \\
\text { S4Settle in the cities }(0.31)\end{array}$ \\
\hline
\end{tabular}

Objective indicators include a series of external factors, which affect the quality of the new generation of 
migrant workers in the social and institutional .In this paper, the objective index is decomposed into the employment condition indexes and the employment security indexes. The employment condition indexes are decomposed into four indexes, the wage payment, the working time, the working environment and the work stability. The specific employment security measures are divided into whether to sign labor contract, whether to join the labor union organization, whether to accept vocational training, whether the company to pay social insurance. Subjective indexes are involved in the new generation of migrant workers in the process of employment related to the quality of employment of various subjective factors, but also achieve the quality of demand. According to the behavior characteristics and psychological characteristics of the individual employment process, this article will be divided into a there-levels indicators, which are subjective index, employment satisfaction index and employment expectation index. From the outside to the inside, to the new generation of migrant workers from the shallower to the deeper investigation of the quality of employment. The job satisfaction index including the satisfaction of salary satisfaction, employer satisfaction, working conditions (including the work places and facilities, work environment, overall satisfaction) on interpersonal relationship satisfaction. Employment expectations include participation in management, the elimination of employment discrimination, access to more employment help, settled in the city. [9]This study believes that the new generation of migrant workers have the characteristics of more willingness to integrate into the city, and the willingness to settle in the city can partly reflect the level of the quality of employment, it is listed as employment expectations index.

To design the new generation of migrant workers' employment quality evaluation index system, the key point is to determine the indicators and weights, scientifically determine the indicators and weights, is the premise of accurate evaluation of the quality of employment. To determine the weight, the main contradiction should be considered. The main contradiction is reflected in two aspects: the choice of indicators. The quality of employment covers a wide range, not all the elements involved into the evaluation index system. The main contradiction existing in the current our country employment quality should be seized ,to focus on the solution of the problem to drive the employment quality of ascension; On the weight distribution, should be according to the various elements in the employment quality of the important degree of different, given different weights. For example, the current default salary, not sign labor contract is the outstanding problems affecting the quality of employment. [10] As a result, the weight of wage income, sign a contract correspondingly. And the new generation of migrant workers pay more attention to development prospects and the opportunity to participate in the management, the weight of the indicators should be tilted.

Based on the analysis of existing academic study of migrant workers employment quality evaluation index system, this research will construct the following new generation migrant workers employment quality evaluation index system, the evaluation system including two first-level indexes, four second-level index, 16 three-level index. This index system research mainly through Delphi expert consultation method to determine the weight of the index system. We chose from the national "211" colleges and universities 12 for migrant workers, employment and other related research experts for advice. The experts selected were all above associate professor title and full two years. Request to the index system for their proper modification Suggestions, and empowerment on set of indicator variables in the questionnaire. In counseling after 4 rounds. Round 1 is the early stage of the theoretical analysis of formation of the relevant indicators to experts for rationality evaluation, by comparison, to abridge individual indicators. Second round main to back to back again to determine the index system of consultation, determine the final index system. 3 rounds of empowerment. Require each expert to the assignment of the indicators, calculate the coordination degree of expertise. 4 wheel value assigned to 
individual expert disagreement is larger for feedback again. Data show that the degree of experts for the new generation of migrant workers to measure the target weights of the index system of overall coordination coefficient reached 0.8 , which is of higher levels.

\section{Conclusions}

This paper summarizes the existing measurement index system, construct a new generation of migrant workers employment quality measurement index system combined with a set of objective and subjective indexes, provides a certain basis and some guidance for the description of the present status of the new generation of migrant workers employment quality level, provides some support and reference for the practice of the relevant departments of the policy making and management department. However, there are some differences in understanding and measurement of the new generation of migrant workers employment quality in different regions, different levels of government, which is also related to different city environment and policy measures, so it is not realistic to design a suitable measurement index system for all policy and environment . In practice, it is necessary to regard it the basis of the index system, combined with the specific environment and measurement characteristics, considering measurable property, data availability other factors related to the new generation of migrant workers, increase or decrease the index flexibly, and adjust the weight of the index accordingly.

\section{References}

[1] Yang Zhiming, Actively solve the problem of the rights and interests of the new generation of migrant workers, Qiu Shi,vol. 2011(17): 40.

[2] Lou Peiminin: Farmers'employmen, edtied by Chinese economic press, China,beijing(2011), in press.

[3] Liu Suhua, The quality of employment: concept, content and its impact on the number of jobs,Population and Family Planning, vol. 2005(07):29-31.

[4] Gao Wei, Construction and application of migrant workers' Employment Quality Evaluation System Based on principal component analysis -- Taking the migrant workers in Shenyang city as an example, China's collective economy, vol. 2005(06) : 86-88.

[5]Peng Guosheng, Research progress on the quality of employment of young migrant workers, Journal of Shanxi Youth Management Institute of management, vol. 2009(22): 1-4.

[6] Lin Zhu, Measurement and analysis of the quality of employment of the new generation migrant workers, Guizhou Social Sciences Vol. 2013 (02):85-89.

[7] Qian Fang, Study on the influencing factors and mechanism of the quality of employment of migrant workers -- Taking Jiangxi Province as an example, Nanchang University, 2014.

[8] Tian Fu Shuang, Chen Zhifa, He Tingting, Cao Lei, An empirical analysis on the influencing factors of the new generation migrant workers' employment quality, Journal of Jiaxing University. Vol. 2005 (03): 78-85.

[9] Lv Jia, Chen Wanming, Construction of measurement index system for the new generation of migrant workers, Jiangsu Agricultural Sciences, Vol. 2014 (42): 478-480.

[10] Chan,J and Selden, M, China's rural migrant workers and labour politics In Guo, Yingjie ed. Handbook on Class and Social Stratification in China. Vol. 2016(2):362-382. 